\title{
A FOTOGRAFIA NA COMPOSIÇÃO DO INVENTÁRIO: ESTUDO DE CASO NO MUSEU HISTÓRICO DE LONDRINA
}

\author{
(1) Ailton Dos Santos Vieira \\ Graduado Universidade Estadua De Londrina, Paraná \\ Ailtonvieira74@Gmail.Com
}

\section{RESUMO}

O desejo em se reunir objetos com o propósito de resguardo da memória coletiva selam os caminhos de nossa própria existência. Para que isto ocorra esses objetos de memória precisam ser organizados, tratados, acomodados, preservados e registrados. Esse é um dos propósitos do Museu Histórico de Londrina. Toda informação tratada têm seu usuário e a documentação museológica se constitui na organização dos objetos sob a guarda no acervo do museu. Ao analisarmos os museus a partir de um olhar para suas estruturas documentais, constata-se que são instituições estreitamente ligadas à informação, e como veículos de informação, têm na conservação e na documentação as bases para se transformar em fontes geradoras e disseminadoras de novas informações. Esta pesquisa segue no propósito investigar a importância da fotografia documentária no inventário e identificando-se a contribuição desta para as práticas museológicas. Para alcançarmos os objetivos desta pesquisa, utilizou-se como Metodologia o Estudo de Caso, especificamente na busca da compreensão dos procedimentos de organização do inventário, e, principalmente, como é o processo fotográfico dos objetos do acervo. Como referencial teórico, o texto discorreu sobre fotografia documentária, documentação museológica, e o uso da fotografia no documento de inventário.

Palavras-chave: Fotografia documentária. Documentação museológica. Inventário. Museu Histórico de Londrina

\section{INTRODUÇÃO}

Ao analisarmos os museus a partir de um olhar para suas estruturas documentais, constata-se que são instituições estreitamente ligadas à informação, e como veículos de informação, têm na conservação e na documentação as bases para se transformar em fontes geradoras e disseminadoras de novas informações.

Existem escassas pesquisas com relação aos documentos informacionais museológicos, principalmente os que investigam as fotografias documentárias neste ambiente. A presente pesquisa segue no propósito de contribuir nesta lacuna, investigando-se a importância da fotografia documentária no documento de inventário do museu. Este documento, o inventário, é essencial para a organização das informações dos objetos contidos no acervo, é um dos mais importantes documentos do museu e mostra-se ser primordial à gestão do acervo.

Assim, delimita-se o objetivo principal desta pesquisa que é estudar os métodos para a organização das fotografias do inventário no Museu Histórico de Londrina. (MHL). Segue-se como objetivos específicos da pesquisa: a) Identificar dos elementos que compõe a documentação museológica; b) Estudar como são estruturados os 
inventários e o uso da fotografia inserida neste documento e, por último, c) Analisar o inventário do Museu Histórico de Londrina quanto á documentação fotográfica no catálogo. O problema que norteia este trabalho se define: Dentro do campo dos estudos museológicos, questiona-se como a fotografia documentária, inserida no inventário, pode contribuir na organização deste documento?

Para alcançarmos os objetivos desta pesquisa, utilizou-se como Metodologia o Estudo de Caso, especificamente na busca da compreensão dos procedimentos de organização do inventário, e, principalmente, como é o processo fotográfico dos objetos do acervo. Como técnica de coleta de dados, optou-se pela entrevista semiestruturada, a análise documental e a observação. Para a realização da pesquisa, iniciou-se com um levantamento bibliográfico sobre a documentação museológica, onde, buscou-se compreender a temática geral da pesquisa.

O termo museu se refere a uma coleção de espécimes de qualquer tipo e está, em teoria, ligado com a educação e/ou com o lazer de qualquer comunidade que visita a instituição (virtual ou fisicamente) (SUANO, 1986).Lembramos que a museologia está inserida dentro da Ciência da Informação, pois trata e estuda a informação contida nos seus variados acervos com o propósito de se fazer o tratamento e a disseminação das informações museológicas.

\section{FOTOGRAFIA COMO DOCUMENTO}

A fotografia é um documento que passar a existir e segue o ritmo da modernidade, o desenvolvimento das técnicas de reprodução foi significativo para a sua popularidade e a extensão. Em sua origem temos dois inventores Nicéphore Niépce e Daguerre.Sougez (2001, p.35) desconstruindo datas atém então tidas como certas afirma que "A fotografia está inventada desde 1816- e não 1822 como afirma o monumento a Niepce em Saint - Loup - de - Varennes, por se terem agarrado a ideia de que a primeira fotografia era a natureza morta".

Sougez (2001, p.48) afirma ainda que sua apresentação aos cientistas, e posteriormente a população em 1839, após François Arago ler uma comunicação na sessão da Academia de Ciências, Arago expos publicamente o processo do daguerreótipo. Segundo Kossoy (2001) a partir da descoberta da fotografia e, com o desenvolvimento da indústria gráfica, possibilitou a multiplicação da imagem fotográfica em quantidades cada vez maiores. Assim para o autor, iniciou-se um novo processo de conhecimento do mundo, porém de um mundo em detalhe.

Neste raciocínio sobre o processo de usos dado aos materiais fotográficos, Albuquerque (2006) afirma que em 1855, alguns anos depois da apresentação na Academia de Ciências de Paris a fotografia passa por uma alteração e está a disposição do público em geral. Com a inserção desde outro consumidor, diferente do ate então, que se resumia a um público muito restrito (intelectuais artistas e cientistas) houve a expansão do consumo da fotografia.

Tal mudança tinha as máquinas e o aperfeiçoamento das técnicas fotográficas como propulsoras, o que barateavam a fotografia a um nível acessível a grande maioria, e levaram a dois usos principais, o privado e o publico, o uso privado esta ligado a memória principalmente em seu contexto familiar. No uso publico a fotografia é 
percebida como um registro, e estava conectada principalmente a área administrativa. Neste estudo o foco será neste último uso.

Albuquerque, (2006 p.39) afirma que a fotografia "Desde seu aparecimento foi imposta com um caráter documentário, baseado no princípio de prova e realidade que a caracterizam. Seu cerne está ligado a valores probatórios usados pela historiografia e pelo direito". As "política, as prisões, os asilos, os hospitais, os departamentos de saúde pública, as escolas e até o próprio sistema moderno de fábricas" (LACERDA, 2008, P.34). Lacerda (2008) ao dissertar sobre a fotografia e seu consumo no universo de instituições desde o século XIX, onde são usadas como registros documentais de suas atividades, tendo como base a sua marca peculiar de "evidencia" e "prova".O valor documental que a fotografia apresenta ou como uma forma de registro é desenvolvido e construído pausadamente, em concordância com este raciocínio.

No domínio das instituições, já existe referencia a existência da utilização de registros fotográficos como evidencia de suas atividades desde praticamente 1840 , como os arquivos de fugitivos criminais das policias da Bélgica, Suíça e do Estado americano da Califórnia.Só mais tarde porém, já na virada do século XX, os arquivos fotográficos de organismos e instituições começam a ser mencionados na literatura sobre a história da fotografia (LACERDA, p.33)

Assim a fotografia se infiltra nas instituições públicas com base em sua função de evidencia, como um apoio técnico ao profissional. Uma importante função de registrar etapas, característica, desenvolvimento de ações entre outro. A fotografia na modernidade adquire status de função documental, concordando conosco Rouillé (2009, p. 27) afirma que:

A modernidade da fotografia e a legitimidade de suas funções documentais apoiam-se nas ligações estreitas que elas mantêm com os mais emblemáticos fenômenos da sociedade industrial: o crescimento das metrópoles e o desenvolvimento da economia monetária; a industrialização; as grandes mudanças nos conceitos de espaço e tempo e a revolução das comunicações; mas, também, a democracia.

Com a revolução industrial, houve um grande avanço e desenvolvimento das ciências e a fotografia alcança papel fundamental nesta nova sociedade industrial. Torna-se um importante instrumento de apoio aos diversos campos científicos. Assim, tal disseminação da fotografia se estendeu a documentação em várias instituições e na organização que compõem os ambientes informacionais e dentro do contexto do museu mais especificamente.

\section{DOCUMENTAÇÃO MUSEOLÓGICA}

Toda a informação tratada têm seu usuário, e a Documentação Museológica se constitui na organização das informações dos objetos sob a guarda no acervo de um museu BARBUY (2008). Assim todos os processos de organização desenvolvidos na instituição, recebem e necessitam de uma base informacional que permitem com que as 
informações se tornem acessíveis ao público e pesquisadores; Ferrez (1994, p.65) sobre a definição de documentação museológica, concorda que:

A documentação de acervos museológicos é o conjunto de informações sobre cada um dos seus itens e, por conseguinte, a representação destes por meio da palavra e da imagem (fotografia). Ao mesmo tempo, é um sistema de recuperação de informação capaz de transformar, como anteriormente visto as coleções do museu de fontes de informação em fontes de pesquisa científica ou em instrumentos de transmissão de conhecimentos.

A documentação sempre acompanha o objeto, desde a sua entrada no museu, registrando alterações de lugar, seu estado de conservação e os empréstimos a outros museus. Por meio destes registros os objetos de um acervo, são identificados, datados, localizados no tempo e espaço, local de fabricação, quais materiais foram empregados na sua fabricação, o seu doador, sua procedência, seu histórico de tramitação, e uso. Oliveira e Silva (2012 p.4) reforçam que

Todos os objetos são passíveis de decodificação, e este mesmo trazem consigo informações registradas através do tempo (a sua estrutura), que diante das constantes pesquisas realizadas pela equipe responsável, poderão ser passadas de forma clara e exata aos que procuram obter conhecimento sobre o mesmo.

Seguindo com nosso raciocínio o ato de documentar em museus, gera os produtos documentários, resultam em documentos, citamos alguns exemplos: documentação de aquisição, livros de tombo, catálogos, dossiês de pesquisa, tesauros, vocabulários controlados e os inventários e outros.

$\mathrm{Na}$ compreensão de Motta (2015, p.28) em seu estudo intitulado Manual Prático de Procedimentos Museológicos, a autora descreve os documentos que compõe a documentação museológica: registro de entrada, livro de tombo/registro e o inventário. Registro de entrada, é uma ficha inicial do objeto e sua função é identificar e dar um número de registro ao objeto.

O Livro de tombo ou registro, ao ser definido por Motta $(2015$, p. 29) é um "[...] documento onde são registrados todos os objetos que compõe o acervo do museu". O Inventário é um livro, um sistema que permite identificar e controlar os objetos do acervo de um museu, ou seja, é o levantamento particular de cada um dos bens de uma instituição. Deve ter os seguintes dados básicos: nome da instituição, número de registro da peça, data de ingresso no museu, nome do objeto, procedência e observações. O livro de inventário oferece um quadro preciso das aquisições do museu e deve ser guardado em local seguro (MARCON, 2010). Desta forma compreende-se que o inventário é um documento importantíssimo dentro de um macro processo da gestão museológica. Concomitante a isto, Marcon (2010, p.28) diz que:

Livro de Inventário é o nome que se dá ao livro, onde fica registrado todo o acervo do museu. Em alguns períodos no Museu da Baronesa, para este tipo de documento foram usados diferentes nomes: Livro Tombo (de 1982 a 2005) e Livro de Inventário (a partir de 2006). Sendo o mesmo documento, optou-se por utilizar neste trabalho a 
nomenclatura Livro de Inventário, pois é o nome pelo qual foi intitulado o mais recente documento de registro do Museu.

O livro de inventário engloba parte do controle patrimonial, serve como fonte de pesquisas posteriores e é uma lista com o quantitativo de todas as peças constantes no museu no momento de sua realização. Deve-se ser anual, ter como objetivo assegurar a garantia no controle do acervo museológico. Esse levantamento também pode ser usado como comprovante de posse do objeto, certificando que a peça pertence a um determinado museu. É uma prática comum que os inventários sejam feitos com esse propósito, ou quando há ocorrência de roubos, desastres, ou ainda quando se pretende reorganizar o acervo. Neste pensamento, Santos (2000, p. 84) afirma que:

É o instrumento legal de garantia de guarda do patrimônio de um museu e dos depósitos que lhe são confiados e oferece um quadro exato das aquisições, depósitos e alienações realizados pela instituição. É também o procedimento administrativo que serve para controlar o acervo, determinar sua natureza, número e localização e todas as peças que o museu tem sob sua responsabilidade. Serve como instrumento de segurança contra ocorrências que escapem ao seu controle, constituindo uma prova necessária que poderá ser requisitada pela justiça em qualquer caso que a envolva.

Segundo Santos (2000, p. 85), um inventário deve conter os seguintes itens: Numeração corrida; Número de registro; Nome ou título do objeto; Técnica ou material; Data (época);Autor (ou marca, ou fabricante).De acordo com Cândido (2006, p. 37-43), um inventário deve passar pelas seguintes etapas; Identificação e registro dos objetos; Classificação dos objetos; Definição de categorias; Arranjo do acervo em coleções; Pesquisa arquivística e bibliográfica; Reprodução fotográfica do acervo; Informatização do projeto de inventário (banco de dados). Sobre a estruturação do inventário, autores têm dissertado sobre o assunto, e, como anteriormente discutido, todo documento necessita-se ser organizado.

Após esta leitura sobre a estrutura de um Livro de Inventário, inferindo-se sobre as informações tipológicas, as organizamos em um quadro para melhor visualização destes elementos estruturais (ver quadro 1), informações estas indicadas pelos autores supracitados:

\begin{tabular}{|l|l|}
\hline $\begin{array}{l}\text { Número de } \\
\text { registro }\end{array}$ & $\begin{array}{l}\text { É a identificação dada pelo museu na entrada da peça. } \\
\text { Numeração única. }\end{array}$ \\
\hline Data de entrada & Data de entrada do objeto no museu. \\
\hline Categoria & $\begin{array}{l}\text { É determinada pela sigla de classificação + função/técnica + uma } \\
\text { numeração que permite saber quantas peças tem nesta categoria }\end{array}$ \\
\hline Data/período & $\begin{array}{l}\text { Data da peça com o máximo de exatidão possível. Período } \\
\text { histórico ao qual pertence à peça pode ser dado se a datação for } \\
\text { incerta. }\end{array}$ \\
\hline Estilo/procedência & $\begin{array}{l}\text { Considerar a soma de características da peça. Ex. Marajoara, } \\
\text { Escola de Ferrara. }\end{array}$ \\
\hline
\end{tabular}




\section{SEMINÁRIO DE PESQUISA EM CIÊNCIAS HUMANAS - SEPECH \\ Humanidades, Estado e desafios didático-científicos \\ Londrina, 27 a 29 de julho de 2016}

\begin{tabular}{|l|l|}
\hline Origem & $\begin{array}{l}\text { Área geográfica onde o objeto foi confeccionado ou encontrado. } \\
\text { Ex.: Escavação na aldeia Pataxó, Pará. }\end{array}$ \\
\hline Material/técnica & $\begin{array}{l}\text { O material geralmente complementa a técnica e vice-versa. } \\
\text { Devem-se usar poucas palavras e o processo de manufatura } \\
\text { deverá ser mencionado. Ex. Colagem sobre tela. }\end{array}$ \\
\hline Função & $\begin{array}{l}\text { O que é, para que serve a peça. A função a qual fora criada a } \\
\text { peça, ex.: bacia, amuleto, lança pendente. }\end{array}$ \\
\hline Inscrições & $\begin{array}{l}\text { Algum registro ou inscrição existente na peça. Ex.: Feita por J. } \\
\text { Baptista 1890. }\end{array}$ \\
\hline Marcas & $\begin{array}{l}\text { Símbolos que identifiquem o fabricante ou época. Deverá ser } \\
\text { transcrita e registrado o local na peça onde se encontra no item } \\
\text { observação. }\end{array}$ \\
\hline Forma \\
aquisição
\end{tabular}

Tabela 1: Informações tipológicas do inventário

Fonte: o autor.

As inferências apontadas acima refletem a intenção em se retratar o máximo de informações sobre a peça inventariada. Observando a estrutura dos campos na tabela 1 , nota-se a complexidade da análise e da representação do objeto inventariado.

\section{Á GUISA DAS CONSIDERAÇÕES}

Após a visita técnica, com os resultados da entrevista e da observação, observou-se que a formação do técnico responsável (TR) pelos objetos tridimensionais do MHL, é em arquivologia, graduado em 2010, com uma especialização em Patrimônio Cultural e Identidade, realizado na UNIFIL em 2011. O TR Possui os seguintes cursos de capacitação na área museológica. A formação diversificada foi vista como um dado positivo pelo pesquisador, visto que o TR demontra uma gama bem variada de competências e ainda pode recorrer aos profissionais especialistas na área, quer de dentro da UEL, ou de outras instituições.

Todo o trabalho documentário realizado no Setor de Documentação é realizado 
por estagiários e técnicos, segundo o TR recebem acompanhamento e são revisados. O MHL utiliza de meios físicos e digitais na composição de sua documentação. O TR ainda mantêm os dois suportes, pois segundo ele, evita-se perda de dados e em alguns casos necessita-se recorrer aos documentos físicos. Utilizam-se de planilhas eletrônicas (Excell), Banco de Imagens (Winisis) e programas usados para o tratamento de imagens (Photoshop e Picasa).

Ao comparar-se com o inventário padrão apontado na literatura (ver figura 1), pode-se analisar que os campos principais fazem-se presentes, entretanto apresenta em alguns campos nomeclaturas diferentes das empregadas, são eles: campo data/período utilizam época, no campo exposições utilizam histórico; apresentam ainda campos extras: - número antigo, estado de conservação, localização no prédio e descrição da peça. no inventário digital (no banco de imagens do acervo no Winisis), apresentam até quatro poses, isto conforme a tipologia de objeto retratado. As Informações técnicas sobre as fotografias utilizadas, empregada nas fotografias dos objetos, o TR respondeu que adota-se a fotografia digital com iluminação artificial na maioria das vezes, apontou que utiliza-se fundo preto ou branco, conforme a cor da peça a ser fotografada.Quando questionado sobre o número de fotografias tiradas do objeto para fim de documentação, o entrevistado respondeu fazer uso de no mínimo duas fotografias, mas, esta quantidade pode variar de acordo com a tipologia do objeto. Neste caso, o TR citou como exemplo uma gravura, afirmando que neste tipo de objeto não vê a necessidade de quatro poses, somente uma é necessária.

Ao analisar, percebe-se a grande importância dos recursos imagéticos para a organização do acervo museológico no MHL. Estes recursos imagéticos indicam servirem como elemento divulgador das novas aquisições quer facilitando a disseminação do objeto na Web ou alcançando uma maior amplitude de divulgação. Ao observar o uso das fotografias digitais constantes no catálogo, compreende-se que o usuário ao ver e copiar a imagem do objeto original, evita-se com essa prática, o manuseio do original e, a ocorrência de extravios. Por este motivo a cópia fotográfica torna-se um fator importante para a preservação dos objetos. Esta ação faz-se com que aumente a vida útil das peças. A fotografia mostra-se assim ser uma importante aliada, ferramenta de preservação e também contribui para a conservação do acervo.

A fotografia demonstra ser uma excelente medida de controle, segurança e de preservação do acervo. Ao invés da necessidade da locomoção até o local onde está depositado o objeto atrás das informações, as fotografias do objeto facilitam este trabalho, pois encurta-se distâncias, reduz-se o tempo e auxilia-se o pesquisador/usuário na sua busca. Com relação às fotografias digitais, estas têm na Web a facilidade de se desdobrar no ciberespaço, alcançando seus públicos, disseminando a cultura e o conhecimento de um povo.

Quanto ao segundo objetivo específico: Estudar como são estruturados os inventários e o uso da fotografia inserida neste documento, ao inferirmos sobre este assunto, os resultados da pesquisa apontaram separar as informações em duas partes. $\mathrm{Na}$ primeira parte as informações intrínsecas e na segunda parte as de cunho extrínseco, como apontado na pesquisa e, complementando, indica-se acrescer no verso do inventário entre quatro a seis fotografias do objeto. Como resultado desta etapa de pesquisa, sugerimos os campos que abrangem todas as informações (intrínsecas e extrínsecas) de um objeto a qual se entende dever constar em um inventário de museu. Estes campos se encontram relacionados nas tabelas 04 e 05 abaixo. Indica-se ainda 


\section{SEMINÁRIO DE PESQUISA EM CIÊNCIAS HUMANAS - SEPECH \\ Humanidades, Estado e desafios didático-científicos \\ Londrina, 27 a 29 de julho de 2016}

como resultado um modelo de formulário de inventário de museu, o formulário apontado se encontra no Apêndice C (p. 65).

\begin{tabular}{|c|c|}
\hline $\begin{array}{l}\text { Número } \\
\text { tombo: }\end{array}$ & $\begin{array}{l}\text { Registro que identifica o objeto como patrimônio do museu por } \\
\text { meio de uma numeração corrida }\end{array}$ \\
\hline $\begin{array}{l}\text { Número } \\
\text { registro: }\end{array}$ & $\begin{array}{l}\text { Tumeração estipulada pelo museu para o registro de identificação } \\
\text { o objeto no acervo museológico }\end{array}$ \\
\hline Número antigo: & iz respeito a um número antigo registrado do objeto \\
\hline $\begin{array}{l}\text { Localização na } \\
\text { instituição: }\end{array}$ & $\begin{array}{l}\text { Trata-se do local onde está o objeto; facilita a sua recuperação física } \\
\text { de forma fácil e eficiente, indicando sua atual localização, ou seja, } \\
\text { se ele está na reserva técnica, na exposição, foi emprestado, e etc. }\end{array}$ \\
\hline $\begin{array}{l}\text { Tipologi } \\
\text { objeto }\end{array}$ & $\begin{array}{l}\text { dentificação quanto á finalidade do objeto, exemplo: um quadro, } \\
\text { m vestido, uma lança, uma faca, entre outros. }\end{array}$ \\
\hline Título: & uando houver indica-lo \\
\hline $\begin{array}{l}\text { Autor ou } \\
\text { Autoridade }\end{array}$ & $\begin{array}{l}\text { Diz respeito aos tipos de autorias envolvidas com o objeto, como, } \\
\text { por exemplo, pintor, artista, estúdios, escultor, fotógrafo, entre } \\
\text { outros. }\end{array}$ \\
\hline $\begin{array}{l}\text { Número de } \\
\text { classificação }\end{array}$ & $\begin{array}{l}\text { Indicar o número correspondente da classificação do objeto } \\
\text { recomenda-se utilizar a numeração padrão adotada pelo museu }\end{array}$ \\
\hline $\begin{array}{l}\text { Descrição } \\
\text { intrínseca }\end{array}$ & $\begin{array}{l}\text { Refere-se à descrição física do objeto, como, por exemplo, a } \\
\text { identificação de marcas ou de algumas assinaturas legíveis, entre } \\
\text { outros. }\end{array}$ \\
\hline $\begin{array}{l}\text { das } \\
0\end{array}$ & o diâmetro. \\
\hline posição & , tela, \\
\hline Procedência & o objeto antes de ser \\
\hline Observação & $\begin{array}{l}\text { m por função complementar a informação que não se nos } \\
\text { contra outros campos registrados }\end{array}$ \\
\hline $\begin{array}{l}\text { Tipo } \\
\text { aquisição }\end{array}$ & $\begin{array}{l}\text { permuta empréstimo, depósito, transferência, } \\
\text { ição. }\end{array}$ \\
\hline $\begin{array}{l}\text { Número } \\
\text { cadastro } \\
\text { doador }\end{array}$ & $\begin{array}{l}\text { Verificar o número do cadastro do doador, se não tiver criar o } \\
\text { cadastro e inserir o número neste campo. }\end{array}$ \\
\hline Ex-proprietário & Visa identificar o antigo dono do objeto (não o doador) \\
\hline Data & ntrada do objeto no acervo do museu \\
\hline $\begin{array}{l}\text { Estado de } \\
\text { conservação }\end{array}$ & $\begin{array}{l}\text { uação de conservação do objeto — se bom, regular, ruim ou } \\
\text { simo. }\end{array}$ \\
\hline
\end{tabular}

Tabela 04: Campos a constar em um inventário de museu

\begin{tabular}{|l|l|}
\hline $\begin{array}{l}\text { Descrição histórico- } \\
\text { simbólica }\end{array}$ & $\begin{array}{l}\text { Aborda as informações que contextualizam o objeto sobre } \\
\text { os aspectos históricos e simbólicos do objeto, transcrever } \\
\text { o máximo das informações levantadas sobre o objeto. }\end{array}$ \\
\hline
\end{tabular}




\section{SEMINÁRIO DE PESQUISA EM CIÊNCIAS HUMANAS - SEPECH Humanidades, Estado e desafios didático-científicos Londrina, 27 a 29 de julho de 2016}

\begin{tabular}{|c|c|}
\hline Período & $\begin{array}{l}\text { Tempo aproximado do objeto (data, década ou o século a } \\
\text { qual ele pertence). }\end{array}$ \\
\hline $\begin{array}{l}\text { Referências } \\
\text { bibliográficas }\end{array}$ & $\begin{array}{l}\text { Trata-se das bases teóricas que possuem relação com o } \\
\text { assunto do objeto e auxiliam na identificação de obras que } \\
\text { tratam do seu contexto }\end{array}$ \\
\hline Objetos as & $\begin{array}{l}\text { Refere-se a outros objetos do acervo que podem estar } \\
\text { diretamente ligados ao objeto descrito (ex. coleção). }\end{array}$ \\
\hline Exposições & Indica todas as exposições pela qual o objeto passou \\
\hline Publicações & Relação das publicações nas quais o objeto foi divulgado \\
\hline Restaurações & $\begin{array}{l}\text { Campo onde se registra todas as intervenções de } \\
\text { restauração que o objeto sofreu }\end{array}$ \\
\hline $\begin{array}{l}\text { Pesquisas/levantament } \\
\text { os }\end{array}$ & Aponta as pesquisas que foram realizadas com o objeto. \\
\hline Autorização de uso & se há restri \\
\hline Observações & $\begin{array}{l}\text { Tem por função complementar a informação que não se } \\
\text { encontra em outros campos }\end{array}$ \\
\hline $\begin{array}{l}\text { Técnica empregada e } \\
\text { responsável pelas } \\
\text { fotografias }\end{array}$ & $\begin{array}{l}\text { Descreve-se a câmera fotográfica utilizada, resolução } \\
\text { fotográfica em DPI, a iluminação empregada, formato da } \\
\text { foto (ex. } 10 \text { X 15), nome do fotógrafo e data; }\end{array}$ \\
\hline Registrado por & $\begin{array}{l}\text { Nome do responsável técnico que descreveu as } \\
\text { informações na ficha }\end{array}$ \\
\hline Data de registro & $\begin{array}{l}\text { Preencher com a data completa (dia, mês e ano) do } \\
\text { registro. }\end{array}$ \\
\hline $\begin{array}{l}\text { No verso quatro a seis } \\
\text { fotografias do objeto }\end{array}$ & $\begin{array}{l}\text { Fotos da frente e verso; dos dois lados e face superior e } \\
\text { inferior do objeto, em se tratando de pinturas de quadro } \\
\text { poderá ser utilizada duas fotografias. }\end{array}$ \\
\hline
\end{tabular}

Tabela 05: Modelo de inventário, parte B.

Fonte: o autor

Quanto aos resultados alcançados no terceiro objetivo específico: Analisar o inventário do MHL quanto à documentação fotográfica no catálogo, percebeu-se a grande importância das fotografias tidas como documento fotográfico para a organização do acervo, estas, quando em formato digital demonstram serem fundamentais para a preservação e a representação do acervo do MHL junto aos seus usuários. Quanto às fotografias, observou-se serem de qualidade, realizadas com técnica profissional, apresentam uma ótima organização estrutural no catálogo e representam muito bem o objeto do acervo.

Esta documentação integrante no banco de imagens, demonstrou ser eficiente no quesito representação e auxílio na organização do acervo do MHL, indicando as informações essenciais como o número de registo, de inventário e a coleção a qual o objeto pertence. Oferecem uma visão holística de todo o acervo do MHL, facilitam assim o trabalho de gestão do acervo. São muitas as informações em que os técnicos e estagiários precisam tratar, organizar e posteriormente disseminar e, as fotografias documentárias vem ao encontro deste propósito.

Nota-se a importância do conhecimento multidisciplinar no ambiente do museu, assim como na biblioteca, no arquivo, pois o fazer do técnico engajado na documentação museológica perpassa por várias competências e, muita das vezes, 
demonstrando-se necessário sair em busca do conhecimento específico encontrado com outros profissionais. $\mathrm{O}$ ciclo nunca se fecha, mas se renova na medida em que recebe um novo item ou uma nova informação.

As fotografias inseridas no inventário recebem na atualidade um lugar de destaque no catálogo do museu. Demonstram-se não apenas ser um excelente representante visual/digital do objeto, atuando também como ícones repletos de sentidos e significados. Através de uma imagem digital pode-se fazer uma ligação com o seu autor, com sua coleção, com seus complementos no acervo, com sua ficha catalográfica, com sua posição no inventário/registro, servindo-se como fonte de disseminação.

\section{REFERÊNCIAS}

ALBUQUERQUE, Ana Cristina de. Catalogação e descrição de documentos fotográficos em bibliotecas e arquivos: uma aproximação comparativa dos códigos AACR2 e ISAD (G). 2006. 188f. Dissertação (Mestrado) - Faculdade de Filosofia e Ciências, Universidade Estadual Paulista, Marília, 2006.

BARBUY, H. Documentação museológica e a pesquisa em museus. In: GRANATO, M., et al. Documentação em Museus/Museu de Astronomia e Ciências Afins - MAST. Rio de Janeiro: MAST, 2008. (MAST Colloquia; 10)

BARROS, A. J. S. Fundamentos da metodologia científica. São Paulo: Pearson Prentice Hall, 2007. p. 112.

MARCON, G. G. Entre fichas, livros e registros: os caminhos percorridos pela Documentação Museológica no Museu Municipal Parque da Baronesa. 2010. 57 p. Monografia (Graduação em Museologia) - Universidade Federal de Pelotas, Pelotas. 2010 .

MOTTA, D. L. A. P. Manual prático de procedimentos museológicos. Sorocaba: Museu de arte contemporânea, 2015. 100 p.

OLIVEIRA, H. S. de; SILVA, E. P.S. Véritas Mouseion: um olhar sobre a documentação museológica. In: Cadernos do Tempo Presente. 2012. Disponível em: $<$ http://www.getempo.org/images/ed6/Artigo_4_1.pdf > . Acesso em: 18 abr. 2015.

PADILHA, R. C.; CAFE, L. M. A. Organização de acervo fotográfico histórico: proposta de descrição. In: Revista de Ciência da Informação e Documentação, v. 5, n. 1, p. 90-111, 2014.

KOSSOY, Boris. Realidades e Fiç̧ões na Trama Fotográfica. Cotia/SP: Ateliê Editorial, 2002.

ROUILLÉ, André. A fotografia: entre documento e arte contemporânea. São Paulo: Senac, 2009 . 
XI SEMINÁRIO DE PESQUISA EM CIÊNCIAS HUMANAS - SEPECH

Humanidades, Estado e desafios didático-científicos

Londrina, 27 a 29 de julho de 2016

SUANO, M. O que é museu. São Paulo: Brasiliense, 101 p., 1986

SOUGEZ, Marie-Loup. História da fotografia. Lisboa: Ediciones Cátedra, 2001. 